Exp. Anim. 56(4), 273-278, 2007

\title{
Vitamin K Deficiency of Germfree Mice Caused by Feeding Standard Purified Diet Sterilized by $\gamma$-Irradiation
}

\author{
Kazuhiro HIRAYAMA ${ }^{1)}$, Koji UETSUKA ${ }^{2)}$, Yoshibumi KUWABARA ${ }^{3)}$, \\ Motoi TAMURA ${ }^{4)}$, and Kikuji ITOH $^{1)}$
}

\begin{abstract}
${ }^{1)}$ Laboratory of Veterinary Public Health and ${ }^{2)}$ Laboratory of Veterinary Pathology, Department of Veterinary Medical Science, Graduate School of Agricultural and Life Sciences, The University of Tokyo, Bunkyo, Tokyo 113-8657, 3)Oriental Yeast Co. Ltd., 3-6-10 Azusawa, Itabashi, Tokyo 174-8505, and ${ }^{4}$ National Food Research Institute, Tsukuba 305-8642, Japan
\end{abstract}

\begin{abstract}
Germfree mice died when they were fed a purified diet of AIN-76 formula sterilized by $\gamma$-irradiation. Vitamin $K$ deficiency was suspected and this study was performed to confirm the cause of the death. Germfree mice were fed purified diets of AIN76 or AIN-93M formula, which were pelleted and sterilized by $\gamma$-irradiation at a dose of 50 $k G y$. One half of the mice fed the AIN-76 diet died within two weeks and the surviving animals were also in poor health, while $91 \%$ of mice fed the AIN-93M diet survived. No hemorrhage was observed grossly in any organs of the surviving animals. Histologically, degeneration with inflammatory cell infiltration was observed as well as hemorrhage and fibrosis in the heart muscles of mice fed the AIN-76 diet. No microscopic lesions were observed in the other organs. Prothrombin time (PT) and activated partial thromboplastin time (APTT) were extremely prolonged when mice were fed the AIN-76 diet. The animals totally recovered when they were intragastrically administered $1 \mu \mathrm{g} /$ day of vitamin $\mathrm{K}_{3}$ from the third day of feeding of the AIN-76 diet, except for PT and APTT which were still slightly longer than in mice fed the AIN-93M diet. The concentration of vitamin $K_{3}$ supplied in the AIN-76 diet decreased to an undetectable level after $\gamma$-irradiation, while the AIN-93M diet contained $240 \mu \mathrm{g} / \mathrm{kg}$ of vitamin $K_{1}$. These results indicate that the deaths of the germfree mice fed the $\gamma$-irradiated AIN-76 diet were caused by vitamin K deficiency. Vitamin $K$ deficiency may cause fatal degeneration of cardiac muscle cells.
\end{abstract}

Key words: germfree mice, myocardium, purified diet, vitamin K deficiency

\section{Introduction}

Mortality attributable to spontaneous hemorrhagic diathesis has been reported mainly in hysterectomy- derived mouse or rat colonies and vitamin $\mathrm{K}$ deficiency has been suggested to be the cause of this condition [1, 5]. When we fed the sterile purified diet of AIN-76 formula to a group of germfree mice, acute death was

(Received 1 June 2006 / Accepted 17 January 2007)

Address corresponding: K. Hirayama, Laboratory of Veterinary Public Health, Department of Veterinary Medical Science, Graduate School of Agricultural and Life Sciences, The University of Tokyo, Bunkyo, Tokyo 113-8657, Japan 
observed. Bleeding from injuries was noted in the suffering animals. Although we did not observe gross hemorrhage, including hemothorax, which has been reported to be a common alteration of the affected animals, at necropsy, vitamin $\mathrm{K}$ deficiency was suspected to be the cause of death and the present study was conducted to confirm this.

\section{Materials and Methods}

\section{Animals}

Germfree BALB/cA mice were bred at our laboratory in flexible vinyl isolators in a room at $24^{\circ} \mathrm{C}$, relative humidity of $60 \%$ and $12 \mathrm{~h} \mathrm{light/dark.} \mathrm{Mice} \mathrm{were} \mathrm{origi-}$ nally from Central Institute for Experimental Animals (Kanagawa, Japan). Animals were fed CMF pelleted diet (Oriental Yeast Co., Tokyo, Japan) sterilized by $\gamma$ irradiation at a dose of $50 \mathrm{kGy}$. Each group of 10-11 male mice was transferred into an autoclavable stainless steel isolator at 20-24 weeks of age.

\section{Diet and experiment}

Purified standard diets of AIN-76 and AIN-93M formula were pelleted and sterilized by $\gamma$-irradiation at a dose of $50 \mathrm{kGy}$ by the Oriental Yeast Co., Tokyo, Japan. The compositions of the AIN-76 and AIN-93M diets and vitamin mixtures are shown in Tables 1 and 2 . The concentrations of vitamin $\mathrm{K}_{3}$ in the AIN-76 diet and vitamin $\mathrm{K}_{1}$ in the AIN-93M diet were measured by the Japan Food Research Laboratories (Tokyo, Japan) using HPLC with a L-column ODS $(150 \times 4 \mathrm{~mm}$, Chemical Evaluation and Research Institute, Tokyo, Japan). The column was maintained at $40^{\circ} \mathrm{C}$. Vitamin $\mathrm{K}_{1}$ was eluted with $0.5 \mathrm{ml} / \mathrm{min}$ of $0.2 \%$ sodium perchlorate/acetonitrile $(1: 1, \mathrm{v} / \mathrm{v})$ and detected with an UV detector (SPD-10AV, Shimadzu, Kyoto, Japan) at wavelength of $254 \mathrm{~nm}$. Vitamin $\mathrm{K}_{3}$ was eluted with $0.8 \mathrm{ml} / \mathrm{min}$ of methanol and detected with a RF-10A $\mathrm{AL}_{\mathrm{XL}}$ fluorescence detector (Shimadzu). The excitation wavelength was $320 \mathrm{~nm}$ and the emission wavelength was $430 \mathrm{~nm}$. A platinum reduction column $(4.0 \mathrm{~mm} \times 15 \mathrm{~mm})$ was located between the HPLC column and the fluorescence detector for post-column reduction. The lipid peroxide value of the diets was also measured by the Japan Food Research Laboratories using the acetate-chloroform method. At the start of the experiment, the diet of each group of mice was changed to the AIN-76 or AIN-93M
Table 1. Compositions of AIN-76 and AIN-93M purified diets $(\%)$

\begin{tabular}{lrc}
\hline & AIN-76 & AIN-93M \\
\hline Casein & 20.0 & 14.0 \\
DL-Methionine & 0.3 & \\
Cornstarch & 15.0 & 46.5692 \\
Dextrinized cornstarch & & 15.5 \\
Sucrose & 50.0 & 10.0 \\
Cellulose powder & 5.0 & 5.0 \\
Corn oil & 5.0 & \\
Soybean oil & & 4.0 \\
Vitamin mixture & 1.0 & 1.0 \\
Mineral mixture & 3.5 & 3.5 \\
L-Cystine & & 0.18 \\
Choline bitartrate & 0.2 & 0.25 \\
Tert-butylhydroquinone & & 0.0008 \\
\hline
\end{tabular}

Table 2. Composition of vitamin mixture for AIN-76 and AIN$93 \mathrm{M}$ diets $(\%)$

\begin{tabular}{|c|c|c|}
\hline & AIN-76 & AIN-93M \\
\hline Vitamin A $(500,000 \mathrm{IU} / \mathrm{g})$ & 0.08 & 0.08 \\
\hline Vitamin $\mathrm{D}_{3}(500,000 \mathrm{IU} / \mathrm{g})$ & 0.02 & 0.02 \\
\hline Vitamin E (500 IU/g) & 1.00 & 1.50 \\
\hline Vitamin $B_{1}$ & 0.06 & 0.06 \\
\hline Vitamin $\mathrm{B}_{2}$ & 0.06 & 0.06 \\
\hline Vitamin $\mathrm{B}_{6}$ & 0.07 & 0.07 \\
\hline \multicolumn{3}{|c|}{ Vitamin $\mathrm{B}_{12}(0.1 \%$ cyanocobalamin in mannitol $)$} \\
\hline & 0.10 & 0.25 \\
\hline Nicotinic acid & 0.30 & 0.30 \\
\hline D-Calcium pantothenate & 0.16 & 0.16 \\
\hline Folic acid & 0.02 & 0.02 \\
\hline D-Biotin & 0.002 & 0.002 \\
\hline Vitamin $\mathrm{K}_{1}$ & & 0.0075 \\
\hline Vitamin $\mathrm{K}_{3}$ & 0.0005 & \\
\hline Sucrose, finely powdered & 97.9495 & 97.2125 \\
\hline
\end{tabular}

diet which the animals accessed freely. One of the two groups fed the AIN-76 diet was administered $1 \mu \mathrm{g} / \mathrm{day}$ of menadione (vitamin $\mathrm{K}_{3}$ ) intragastrically from the third day of the AIN-76 diet. The condition of the animals was observed daily. After 14 days of the experimental diets, the surviving animals were sacrificed and whole blood was withdrawn from the caudal vena cava. One tenth the volume of the whole blood of $3.8 \%$ sodium citrate solution was added to the whole blood and plasma was separated. Plasma prothrombin time (PT) and activated partial thromboplastin time (APTT) were measured with commercial kits (Thromborel ${ }^{\circledR} \mathrm{S}$ and Pathromtin, Dade Behring Marburg, Marburg, Ger- 
many). The brain, heart, lungs, liver, stomach, large and small intestines, spleen, kidneys and testes were collected and fixed in $10 \%$ buffered formalin for further histopathological investigation. The tissues were embedded in paraffin, sectioned at $4 \mu \mathrm{m}$ and stained with hematoxylin and eosin.

\section{Statistical analysis}

Survival rates of the groups were compared by the $\chi$ square test and the mean values were analyzed by Student's $t$-test.

\section{Results}

\section{General conditions and survival of the mice}

Mice fed only the AIN-76 formula diet without vitamin $\mathrm{K}$ treatment exhibited non-specific clinical signs from the third day of feeding. The animals appeared depressed and lethargic, with hunched backs and an ungroomed appearance. Bleeding from injuries was also apparent in some animals. The mice in this group started to die from the eighth day of feeding and only half of the animals had survived at the end of the experiment, after 14 days of feeding (Fig. 1). The surviving animals were also in poor health. Mice fed the AIN-76 diet recovered when they were intragastrically administered $1 \mu \mathrm{g}$ /day of vitamin $\mathrm{K}_{3}$ from the third day of the diet and all animals in this group survived for 14 days. In the group of mice fed the AIN-93M diet, one of 11 animals died on the sixth day but the rest of the animals survived for 14 days. The survival rate after 14 days of the mice fed only the AIN-76 diet without vitamin $\mathrm{K}$ treatment was significantly lower than those of the other groups $(P<0.05)$.

\section{Gross pathologic findings}

No apparent lesions, including hemorrhage, were observed grossly in any organs of the surviving animals in the three groups at autopsy after 14 days of feeding. Necropsies were also performed on some of the dead mice that were not decomposed or cannibalized, but no gross lesions, including hemorrhage in the intestinal tract and hemothorax, were observed.

\section{Histopathological findings}

Histologically, degeneration of the cardiac muscle cells with hemorrhage, infiltration of inflammatory cells

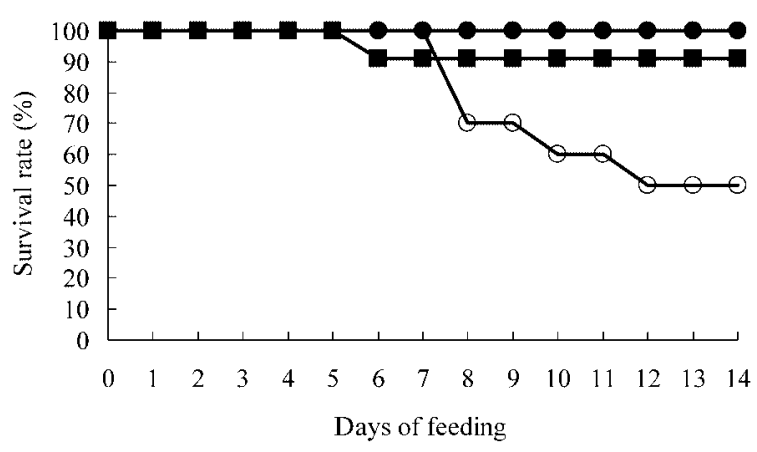

Fig. 1. Survival rate of germfree mice fed a purified diet of AIN-93M or AIN-76 formula with or without intragastric administration of vitamin $\mathrm{K}_{3}$. $\mathrm{O}$ : AIN-76 diet, : AIN-76 diet and oral vitamin $\mathrm{K}_{3}, \boldsymbol{\square}$ : AIN$93 \mathrm{M}$ diet.

and proliferation of collagenous fibers in the interstitium were observed in the ventricular myocardium of mice fed the AIN-76 diet (Fig. 2A). These lesions were mainly distributed in the subepicardial myocardium. No microscopic lesions were observed in the other organs. Microscopic lesions were not found in mice fed the AIN-76 diet and administered vitamin $\mathrm{K}_{3}$ from the third day of feeding, although the myocardium showed slight edematous loosening of the interstitial tissue (Fig. 2B). No microscopic lesions were observed in mice fed the AIN-93M diet.

\section{Hematological findings}

Plasma PT and APTT were extremely prolonged in mice fed the AIN-76 diet without vitamin K treatment, and the plasma did not coagulate within $300 \mathrm{~s}$ in both tests. PT and APTT were dramatically shortened to $11.5 \pm 2.4 \mathrm{~s}$ and $45.9 \pm 23.3 \mathrm{~s}$ by intragastric vitamin $\mathrm{K}_{3}$ administration, respectively. However, both PT and APTT in mice fed the AIN-76 diet and administered vitamin $\mathrm{K}_{3}$ were still significantly longer than in mice fed the AIN-93M diet $(8.9 \pm 1.7 \mathrm{~s}$ and $26.3 \pm 3.5 \mathrm{~s}$, respectively, $P<0.05$ ).

\section{Analysis of the diets}

The concentration of vitamin $\mathrm{K}_{3}$ in the AIN-76 diet, which was $50 \mu \mathrm{g} / \mathrm{kg}$ in the formula, decreased to an undetectable level after pelletting and irradiation (Table 3). The concentration of vitamin $\mathrm{K}_{1}$ in the AIN-93M diet was maintained at $240 \mu \mathrm{g} / \mathrm{kg}$ even after irradiation; it was added at a concentration of $750 \mu \mathrm{g} / \mathrm{kg}$ in the formula. Lipid peroxide values were comparable in the 

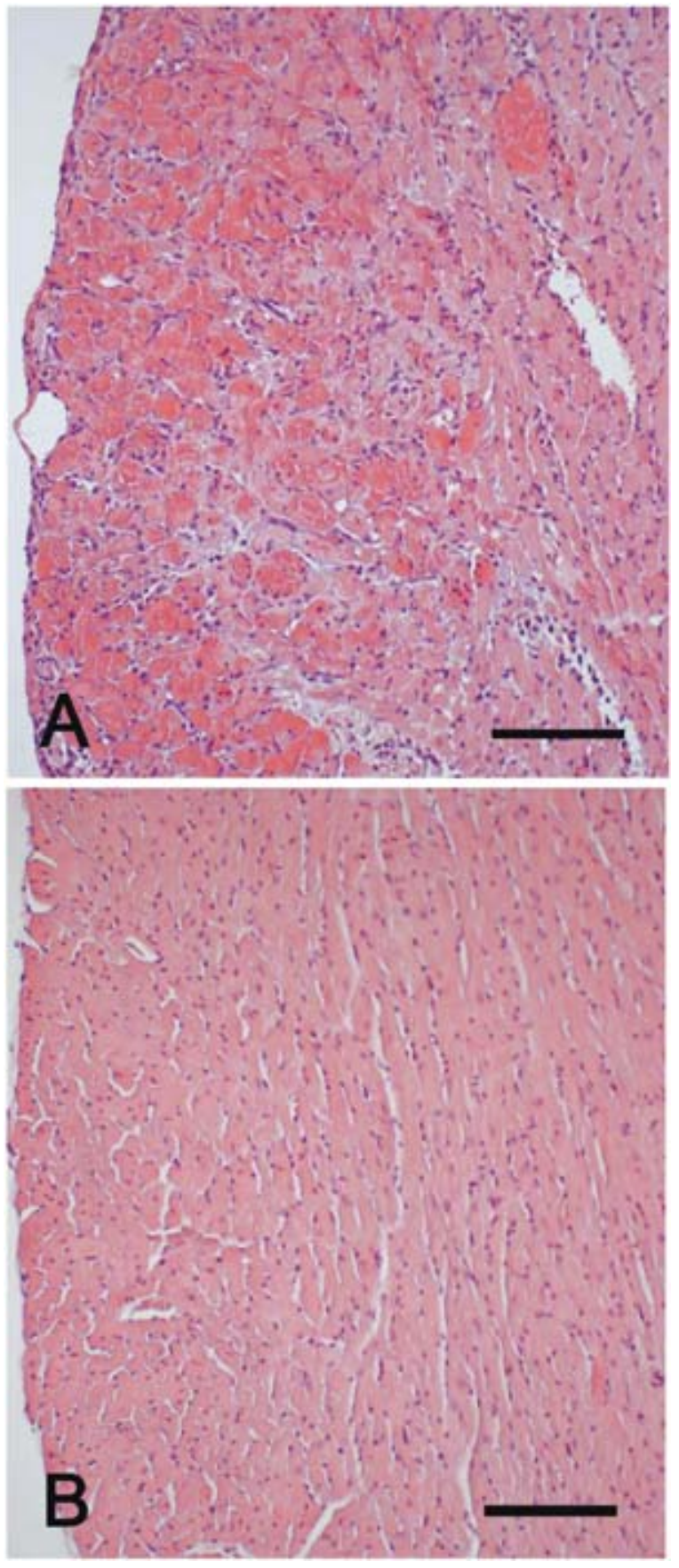

Fig. 2. Histopathological findings of the left ventricle of the heart of germfree mice fed a purified diet of AIN-76 formula with or without intragastric administration of vitamin $\mathrm{K}_{3}$. $\mathrm{H} \& \mathrm{E}$ stain. Bar $=150 \mu \mathrm{m}$. A: AIN-76 diet, B: AIN-76 diet and intragastric vitamin $\mathrm{K}_{3}$. Degeneration with hemorrhage, infiltration of inflammatory cells and fibrosis were observed in the subepicardial myocardium of mice fed the AIN-76 diet without vitamin K treatment. Lesions were not found in mice fed the AIN-76 diet and orally administered vitamin $\mathrm{K}_{3}$, although the myocardium showed slight edematous loosening of the interstitial tissue.
Table 3. Concentrations of vitamin $\mathrm{K}$ and lipid peroxide in the purified diet of AIN-76 and AIN-93M formula after 50 kGy $\gamma$-irradiation

\begin{tabular}{lcc}
\hline$(/ \mathrm{kg})$ & AIN-76 & AIN-93M \\
\hline Vitamin K $(\mu \mathrm{g})$ & $\mathrm{ND}^{\mathrm{a}, \mathrm{b}}$ & $240^{\mathrm{c}}$ \\
Lipid peroxide (meq) & 60.7 & 62.7 \\
\hline
\end{tabular}

aNot detected. ${ }^{\mathrm{b}}$ As vitamin $\mathrm{K}_{3}$. ${ }^{\mathrm{c}} \mathrm{As}$ vitamin $\mathrm{K}_{1}$.

AIN-76 and AIN-93M diets, and were 60.7 and 62.7 $\mathrm{meq} / \mathrm{kg}$, respectively.

\section{Discussion}

A disease characterized by spontaneous hemorrhage and death was first described as an epizootic disease of mice in 1943 at the University of Wisconsin [4].Several other reports followed [5, 9, 11]. A variety of factors other than vitamin $\mathrm{K}$ deficiency secondary to altered intestinal microflora of this disease have been suspected of causing or contributing to the outbreaks [5], including infectious agents [4], ethylene glycol contamination of cage bedding [11] and increased dietary lipoperoxides complicated by vitamin $\mathrm{K}$ and/or E deficiency [9]; however, the factor(s) responsible for the disease were not fully identified in these reports. Allen et al. [1] first described the mortality of mice attributable to hemorrhagic diathesis in NIH Genetic Resource colonies in 1971. They concluded that the cause of hemorrhagic cardiomyopathy and hemothorax was vitamin $\mathrm{K}$ deficiency based on controlled studies using germfree mice given a vitamin K-free diet and conventional mice given warfarin in their diet.

In the present study, the mortality rate of germfree mice fed the $\gamma$-irradiated diet of AIN-76 formula was $50 \%$, which was significantly higher than that of the mice fed the AIN-93M formula diet. PT and APTT were extremely prolonged in the surviving mice fed the AIN-76 formula diet compared to the mice fed the AIN$93 \mathrm{M}$ formula diet. Although the AIN-76 formulation contains $50 \mu \mathrm{g} / \mathrm{kg}$ of menadione (vitamin $\mathrm{K}_{3}$ ), the diet with the AIN-76 formula contained no detectable amount of vitamin $\mathrm{K}_{3}$ after pelleting and irradiation. Mortality and symptoms were decreased when the mice fed the AIN-76 formula diet were intragastrically administered $1 \mu \mathrm{g} /$ day of menadione. The lipid peroxide concentrations of both diets were comparable. These 
results suggest that the death of germfree mice fed the $\gamma$-irradiated AIN-76 diet was caused by vitamin K deficiency, although it is reported that casein, $200 \mathrm{~g} / \mathrm{kg}$ in the diet, contains an average of about $800 \mu \mathrm{g} / \mathrm{kg}$ vitamin $\mathrm{K}_{1}$ and an additional $160 \mu \mathrm{g} / \mathrm{kg}$ of vitamin $\mathrm{K}_{1}$ was added to the AIN-76 diet [13].

In 1973, an ad hoc committee was formed by the American Institute of Nutrition (AIN) to identify the dietary standards for nutritional studies with laboratory rodents. The committee has established guidelines to help scientists with limited experience in experimental nutrition. The diet following the committee's recommendation was designated the AIN-76 diet [2]. Although the AIN-76 diet has given good results in terms of animal growth, appearance and survival, a few problems, possibly including excessive destruction of menadione or interference with its utilization with a resultant vitamin $\mathrm{K}$ deficiency, have been reported [3]. The committee then made the recommendation that the amount of vitamin $\mathrm{K}$ should be increased 10-fold to $500 \mu \mathrm{g} / \mathrm{kg}$, and the modified diet has been designated AIN-76A [3]. Based on further discussion on the reported nutritional and technical problems encountered with the AIN-76 and AIN-76A diets at a workshop held in 1989 and their recommendations [12], two new formulations, AIN-93G for growth, pregnancy and lactation, and AIN-93M for adult maintenance, were proposed and adopted [13]. Although no changes in vitamin K were suggested at the 1989 workshop [12], the amount of vitamin $\mathrm{K}$ was arbitrarily set at $750 \mu \mathrm{g} /$ $\mathrm{kg}$ diet and phylloquinone (vitamin $\mathrm{K}_{1}$ ) was used instead of menadione as the form of vitamin K. Thus, although these revised formulations of standard purified diet for laboratory rodents have been established and contain more vitamin $\mathrm{K}$, the AIN-76 diet remains a well-known standard diet and researchers should take care to use purified diets, especially when they use germfree animals.

Although hypoprothrombinemia due to vitamin $\mathrm{K}$ deficiency is occasionally observed in newborn infants and anticoagulant drug- or antibiotic-treated adults, primary vitamin $\mathrm{K}$ deficiency is uncommon in both animals and humans because vitamin $\mathrm{K}$ is distributed widely in plant and animal tissues, and intestinal flora synthesize menaquinones in amounts that probably supply the nutritional requirement. Therefore, vitamin $\mathrm{K}$ deficiency has often been studied in rats or mice fed a special diet deficient in vitamin $\mathrm{K}[6,7,10,14]$. Komai et al. [8] proposed that germfree mice fed a vitamin $\mathrm{K}$ deficient diet were a useful model for studying hemorrhagic diseases without metabolic changes by the administration of antibiotics or vitamin $\mathrm{K}$ antagonists. In the present study, we produced vitamin $\mathrm{K}$ deficiency merely by feeding a commercially available purified diet with AIN-76 formula, pelleted and irradiated, to germfree mice.

Histologically, mice fed the AIN-76 diet for 14 days in the present study showed myocardial degeneration with hemorrhage, infiltration of inflammatory cells and fibrosis in heart ventricles. In previous studies, multifocal hemorrhage and necrosis with varying degrees of acute inflammation and fibrosis have been reported in vitamin K-deficient mice [1, 5, 9, 11]. Coagulation defects, including prolonged PT, have also been reported $[5,11]$. These findings are similar to those found in the present study; however, the key findings in previous studies were hemorrhage in various organs, especially hemothorax, which was not observed in the present study. No gross hemorrhage was observed in any organ. Lesions were found only in the heart muscle both grossly and histologically. The results of the present study indicate that vitamin $\mathrm{K}$ deficiency may primarily cause fatal myocardial degeneration with hemorrhage. The mechanisms by which vitamin $\mathrm{K}$ deficiency causes myocardial degeneration with hemorrhage and the clinical importance of such lesions due to vitamin $\mathrm{K}$ deficiency should be studied further.

\section{References}

1. Allen, A.M., Hansen, C.T., Moore, T.D., Knapka, J., Ediger, R.D., and Long, P.H. 1991. Hemorrhagic cardiomyopathy and hemothorax in vitamin $\mathrm{K}$ deficient mice. Toxicol. Pathol. 19: 589-596.

2. American Institute of Nutrition. 1977. Report of the American Institute of Nutrition ad hoc committee on standards for nutritional studies. J. Nutr. 107: 1340-1348.

3. American Institute of Nutrition. 1980. Second report of the ad hoc committee on standards for nutritional studies. $J$. Nutr. 110: 1726.

4. Angevine, D.M. and Furth, J. 1943. A fatal disease of middle-aged mice characterized by myocarditis associated with hemorrhage in the pleural cavity. Am. J. Pathol. 19: 187-195.

5. Fritz, T.E., Tolle, D.V., and Flynn, R. 1968. Hemorrhagic diathesis in laboratory rodents. Proc. Soc. Exp. Biol. Med. 128: $228-234$. 
6. Groenen-van Dooren, M.M.C.L., Ronden, J.E., Soute, B.A.M., and Vermeer, C. 1995. Bioavailability of phylloquinone and menaquinones after oral and colorectal administration in vitamin K-deficient rats. Biochem. Pharmacol. 50: 797-801.

7. Kindberg, C.G. and Suttie, J.W. 1989. Effect of various intakes of phylloquinone on signs of vitamin K deficiency and serum and liver phylloquinone concentrations in the rat. J. Nutr. 119: 175-180.

8. Komai, M., Shirakawa, H., and Kimura, S. 1988. Newly developed model for vitamin $\mathrm{K}$ deficiency in germfree mice. Int. J. Vit. Nutr. 58: 55-59.

9. Kusewitt, D.F., Wagner, J.E., Dixon, L.W., and Anderson, P.A. 1984. Fatal myocarditis in mice fed rancid purified feed. Lab. Anim. Sci. 34: 70-74.

10. Matschiner, J. and Doisy Jr., E.A. 1965. Effect of dietary protein on the development of vitamin $\mathrm{K}$ deficiency in the rat. J. Nutr. 86: 93-99.

11. Meier, H., Allen, R.C., and Hoag, W. 1962. Spontaneous hemorrhagic diathesis in inbred mice due to single or multiple "prothrombin-complex" deficiencies. Blood 19: 501-514.

12. Reeves, P.G. 1989. AIN-76 diet: should we change the formulation? J. Nutr. 119: 1081-1082.

13. Reeves, P.G., Nielsen, F.H., and Fahey Jr., G.C. 1993. AIN-93 purified diets for laboratory rodents: final report of the American Institute of Nutrition ad hoc writing committee on the reformulation of the AIN-76A rodent diet. J. Nutr. 123: 1939-1951.

14. Uchida, K., Nomura, Y., Takase, H., Harauchi, T., Yoshizaki, T., and Nakao, H. 1986. Effects of vitamin Kdeficient diets and fasting on blood coagulation factors in conventional and germ-free rats. Jpn. J. Pharmacol. 40: $115-122$. 